\title{
Letreiros comerciais da cidade de Lençóis: um diálogo com a antropologia de Darcy Ribeiro
}

\author{
Commercial signs from Lençóis city: a dialogue with Darcy Ribeiro's Anthropology
}

LOPES, Juliana Gonçalves; Especialista em Direção de Arte e Comunicação; Centro Universitário Belas Artes de São Paulo

juliana.sepol@gmail.com

BUONANO, Débora Gigli; Doutora em Educação, Arte e História da Cultura; Centro Universitário Belas Artes de São Paulo

debora.buonano@belasartes.br

\section{Resumo}

A riqueza imagética da cultura popular brasileira é resultado da complexa formação étnica de seu povo, geradora de uma cultura sincrética e plural, que influencia intensamente artistas e designers. Entretanto, é notável a existência de um melhor aproveitamento dessa influência quando conceitos e ferramentas da Antropologia são associados ao Design. Partindo dessa premissa, o presente artigo faz uma análise dos letreiros comerciais, produzidos por letristas populares, da cidade baiana de Lençóis, sob a perspectiva dos estudos do antropólogo Darcy Ribeiro. Identificar a forma como a cultura brasileira se materializa nesse objeto de estudo, possibilitou uma compreensão mais profunda desse povo e seu contexto, abrindo novas possibilidades estéticas aos designers que trabalham com a temática brasileira.

Palavras Chave: Darcy Ribeiro; Tipografia vernacular; Antropologia do Design.

\begin{abstract}
The imagetic richness of Brazilian popular culture is the result of the complex ethnic formation of its people, which generates a syncretic and plural culture, which strongly influences artists and designers. However, it is notable the existence of a better use of this influence when concepts and tools of Anthropology are associated with Design. Based on this premise, this article analyzes the commercial signs produced by popular lettering artist from Bahia's city Lençóis, from the perspective of the anthropologist Darcy Ribeiro. Identifying the way Brazilian culture materializes in this object of study has enabled a deeper understanding of this people and their context, opening up new aesthetic possibilities for designers working on Brazilian themes.
\end{abstract}

Keywords: Darcy Ribeiro; Vernacular typography; Design Anthropology. 


\section{Introdução}

A formação do povo brasileiro é resultado de um intrincado sincretismo humano, gerado a partir de três matrizes étnicas distintas - a indígena, a portuguesa e a africana -, que, a despeito do violento processo de mestiçagem, deram origem a esse povo novo e único, caracterizado por uma rica pluralidade social e cultural. Essa diversidade se expressa nas mais variadas manifestações populares, que no entrechoque de signos e símbolos antagônicos, produzem uma cultura visual genuína e inspiradora.

A cultura popular já influenciou diversos artistas brasileiros, que ao utilizá-la como tema, valorizam e fortalecem a identidade nacional. O Movimento Armorial ${ }^{1}$, de Ariano Suassuna, por exemplo, lançou um novo olhar à cultura popular nordestina com o objetivo de atribuir a ela um caráter erudito. Já o designer Aloísio Magalhães conferiu ao design um papel social, compreendendo-o como uma ferramenta para o desenvolvimento econômico e cultural do país, ao utilizá-lo como meio para incorporar elementos de nossa cultura nas ações governamentais. Exemplos como esses confirmam como o popular pode ser uma fonte visual enriquecedora para artistas e designers. No entanto, é preciso que esses profissionais procurem meios de aprofundar a compreensão de nossa história e cultura, para que a apropriação desse conteúdo possa ser mais ampla e consistente. No documentário O povo brasileiro (2010), de Isa Grinspum Ferraz, o antropólogo Roberto Costa Pinho alerta: "a pior coisa que se pode fazer com uma cultura é se apropriar dessa cultura como uma coisa exótica, porque o Brasil oferece não exotismos, mas oferece uma história de criação civilizacional das mais interessantes do mundo". Dessa forma, conciliar conceitos e ferramentas da Antropologia às práticas do Design se faz necessário para uma abordagem mais coerente e eficaz da cultura brasileira. Essa interdisciplinaridade vem se expandindo nos últimos anos, com a criação inclusive de programas de mestrado com o tema, que possibilitam ao designer acesso a uma nova dimensão do usuário e de seu contexto.

Seguindo essa tendência, este artigo propõe uma análise dos letreiros comerciais da cidade baiana de Lençóis, que possui parte de seu conjunto arquitetônico tombado ${ }^{2}$ pelo Instituto do Patrimônio Histórico e Artístico Nacional (IPHAN), relacionando sua produção vernacular ${ }^{3}$ aos estudos do antropólogo Darcy Ribeiro ${ }^{4}$ em seu livro $O$ povo brasileiro, com o objetivo de compreender como a cultura dessa população se materializa nesse objeto de análise.

\footnotetext{
1 O Movimento Armorial foi idealizado pelo dramaturgo paraibano Ariano Suassuna e lançado na década de 1970, na cidade de Recife (PE). Inspirado nas ideias nacionalistas do modernismo e na brasilidade nordestina da obra de Gilberto Freyre, Suassuna propôs a construção de uma arte erudita autêntica brasileira, a partir das raízes populares do Nordeste, atuando no âmbito do teatro, da música, da poesia e das artes gráficas.

2 Utilizado como dispositivo legal para proteger e preservar bens móveis e imóveis relativos à memória nacional, o tombamento é de competência das três esferas governamentais, que atuam por intermédio de leis ou órgãos, como o IPHAN, responsáveis pela preservação. Qualquer cidadão pode fazer a solicitação de tombamento, no entanto, todos os pedidos passam por uma avaliação técnica que, entre coisas, analisa a relevância histórica e cultural do bem. Após a aprovação do tombo e notificação do proprietário, o bem passa a ser protegido legalmente contra destruições ou descaracterizações.

3 Segundo Finizola (2010, p. 30), “a utilização do termo vernacular é empregada para definir aqueles artefatos autênticos da cultura de determinado local, geralmente produzidos à margem do design oficial".

4 Darcy Ribeiro (1922-1997), renomado antropólogo, educador, romancista e político brasileiro, nascido em Montes Claros (MG), se dedicou ao estudo dos povos indígenas brasileiros e da formação dos povos americanos com a finalidade de compreender o impacto do processo civilizatório na história atual da América e do Brasil.
} 
Estudar a cultura popular e a identidade brasileira partiu de uma necessidade pessoal e social de resgatar a autoestima nacional num momento de profunda crise. Ao mesmo tempo que o recorte da pesquisa sobre o trabalho vernacular de Lençóis, lançou um olhar sobre a importância da tradição oral na sociedade, que suscita a sensação de pertencimento e união de um grupo.

A pesquisa foi iniciada em campo, com uma visita à Lençóis, onde foi feito o registro fotográfico de parte dos letreiros comerciais da cidade. Em seguida, analisou-se as atribuições formais dos letreiros, e realizou-se uma entrevista com Gil das Pedras, letrista da cidade, para investigar a relação entre sua produção popular e a história da cidade e identificar se em algum momento esse vínculo é feito intencionalmente. Somada a essa coleta de dados, fez-se uma pesquisa bibliográfica com o propósito de assimilar os universos da tipografia vernacular e da Antropologia do Design e, com isso viabilizar a associação dos estudos de Darcy Ribeiro com os letreiros analisados. A esse trabalho, também foi importante integrar a pesquisa da história e da cultura da cidade, compreendidas como pontos de convergência entre a antropologia e o objeto de estudo.

Este trabalho pretende analisar a linguagem gráfica popular brasileira a partir de uma abordagem antropológica, propondo novas possibilidades visuais e de compreensão do ser brasileiro aos designers que trabalham com essa temática.

\section{Darcy Ribeiro e o povo brasileiro}

Durante o seu exílio, entre os anos de 1964 e 1976, Darcy Ribeiro ficou muito desiludido com a situação política brasileira e, numa tentativa de compreender a problemática social do país, iniciou a produção da coleção Estudos de Antropologia da Civilização, composta por seis volumes: $O$ processo civilizatório, A civilização, O dilema da América Latina, Os brasileiros: 1. A teoria do Brasil, Os índios e a civilização e $O$ povo brasileiro.

Lançado em 1995, o livro O povo brasileiro é considerado a conclusão dos mais de 30 anos de estudo do antropólogo. Nele, o autor traçou, sob uma perspectiva nova e original, um retrato histórico-antropológico da formação do povo brasileiro, para justificar sua constituição e estratificação social atual. Para melhor abordar a heterogeneidade sociocultural do Brasil, Darcy Ribeiro dividiu sua formação em seis culturas distintas, configuradas a partir de suas matrizes étnicas formadoras, do seu espaço territorial de origem e da influência socioeconômica vivida por elas.

\footnotetext{
Elas são representadas pela cultura crioula, que se desenvolveu nas comunidades da faixa de terras frescas e férteis do Nordeste, tendo como instituição coordenadora fundamental o engenho açucareiro. Pela cultura caipira, da população das áreas de ocupação dos mamelucos paulistas, constituída, primeiro, através das atividades de preia de índios para a venda, depois, da mineração de ouro e diamantes e, mais tarde, com as grandes fazendas de café e a industrialização. Pela cultura sertaneja, que se funde e difunde através dos currais de gado, desde o Nordeste árido até os cerrados do Centro-Oeste. Pela cultura cabocla das populações da Amazônia, engajadas na coleta de drogas da mata, principalmente nos seringais. Pela cultura gaúcha do pastoreio nas campinas do Sul e suas duas variantes, a matuta-açoriana (muito parecida com a caipira) e a gringocaipira das áreas colonizadas por imigrantes, predominantemente alemães e italianos. (RIBEIRO, 2006, p. 246-247).
}

Os "brasis" gerados a partir da miscigenação entre povos e culturas se mesclam num processo continuado de transformação, no qual curiosamente estabelece o Brasil como um povo unificado em uma só nação. Entretanto, conhecer a origem de nossa formação humana ainda é fundamental para refletirmos o que somos hoje. Compreender quem é o povo brasileiro, é compreender sua cultura e a forma com a qual ela se expressa. 


\title{
3 Um olhar antropológico sobre os letreiros comerciais de Lençóis
}

Os primeiros encontros da imagem com a Antropologia aconteceram no final do século XIX, com o uso da fotografia e do cinema como instrumentos de documentação das práticas culturais ameaçadas do Oriente e das Américas. Essa antropologia de urgência delineou o que seria denominado mais tarde Antropologia Visual.

Nos últimos anos, devido ao intenso apelo contemporâneo à imagem, o campo de atuação da Antropologia Visual se expandiu, fazendo-se necessária sua associação a outras disciplinas como a Arte e o Design.

A Antropologia do Design desenvolveu-se à medida que o objeto e a imagem foram identificados como portadores de discursos e configurações sociais e culturais, e o designer que os concebe como um agente dessa significação. Essa produção imagética se transforma em um artefato cultural que carrega em si as apropriações e processos culturais de uma sociedade.

\begin{abstract}
A comunicação se estabelece por meio de signos e estes se transformam culturalmente em significações. As representações são justamente as manifestações exteriores dessa significação construída pelos indivíduos em seu fazer cotidiano. Uma representação não é uma realidade observável, mas um conjunto abstrato que só conhecemos por certas manifestações exteriores que reconstituímos mediante relatos, imagens e narrativas. (BARBOSA, 2006, p. 55).
\end{abstract}

Para a designer Zoy Anastassakis (2008), associar Design e Antropologia implica investigar as relações que o designer, visto como um "personagem social", estabelece com o mundo à sua volta.

Os letreiros comerciais analisados nesse estudo não foram produzidos por designers, por isso, o papel de decodificar os signos sociais e culturais no processo de criação dos letreiros foi dos próprios letristas e artesãos populares, numa construção simbólica muitas vezes intuitiva.

O livro $O$ povo brasileiro, de Darcy Ribeiro, serviu de guia para a análise antropológica dos letreiros, complementada pela visita de campo à Lençóis, que possibilitou observar a relação da população com a história local. Nota-se nos habitantes um interesse e orgulho pela cidade e sua história, que se refletem no zelo pelas edificações tombadas e pelo Parque Nacional da Chapada Diamantina (PNCD), localizado em seu entorno.

A partir dessa metodologia, foi traçada uma correspondência entre a formação populacional da região e a expressão cultural desse grupo, para, em seguida, ser observada a materialização desses conceitos nos letreiros.

\section{Os "brasis" da cidade de Lençóis}

Com clima semiárido, Lençóis está localizada na região centro-sul do estado baiano, dentro da área de proteção do Parque Nacional da Chapada Diamantina. Segundo o Instituto Brasileiro de Geografia e Estatística (IBGE), em 2017, a população estimada da cidade era de 11.636 habitantes, distribuídos em uma área total de $1.283,328 \mathrm{~km}^{2}$, que incluem também os distritos de Afrânio Peixoto e Coronel Octaviano Alves. Após a proibição da extração de diamantes na região e a criação do PNCD, o turismo tornou-se a principal atividade econômica da cidade, que explora principalmente as belezas naturais do Parque. Sua história e localização convergem para a influência de duas culturas na formação de sua população, a sertaneja e a caipira. 
O início da ocupação da região é marcado pela presença de fazendeiros dedicados à criação de gado, meio de vida próprio da cultura sertaneja. Uma população que se forma a partir do fenótipo branco, de um vaqueiro pobre que se distancia da costa para proteger as lavouras de canade-açúcar do seu gado. Essa diáspora possibilita o encontro, nem sempre amistoso, com o indígena, gerando a miscigenação entre essas duas matrizes. Sua economia pastoril é apoiada no fornecimento de carne e couro à produção açucareira.

\footnotetext{
O sertanejo arcaico caracteriza-se por sua religiosidade singela tendente ao messianismo fanático, por seu carrancismo de hábitos, por seu laconismo e rusticidade, por sua predisposição ao sacrifício e à violência. E, ainda, pelas qualidades morais características das formações pastoris do mundo inteiro, como o culto da honra pessoal, o brio e a fidelidade a suas chefaturas. [...] Suas duas formas principais de expressão foram o cangaço e o fanatismo religioso, desencadeados ambos pelas condições de penúria que suporta o sertanejo, mas conformadas pelas singularidades do seu mundo cultural. (RIBEIRO, 2006, p. 320).
}

Apesar das dificuldades oriundas das condições adversas do clima da região e da pobreza proveniente disso, esse povo resiliente se expressa de forma muito criativa e lúdica, através de sua cultura popular. Na música, com o baião, na literatura, com o cordel, e na arte de suas festas religiosas, o sertanejo cria um colorido alegre e de rica diversidade visual.

Em Lençóis, é possível encontrar traços dessa cultura popular no imaginário coletivo da população. Exemplo disso é o nome do restaurante Maria Bonita, uma referência à esposa do líder do cangaço ${ }^{5}$, Virgulino Ferreira da Silva, o Lampião. A literatura de cordel também é vendida como produto local nas lojas de conveniência, e as festas juninas são um dos principais acontecimentos da cidade.

Figura 1 - Letreiro do restaurante Maria Bonita, Lençóis (BA).

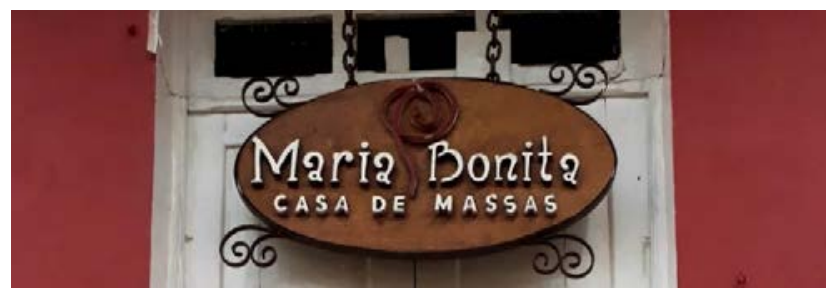

Fonte: a autora (2017)

Em 1844, quando o primeiro diamante foi encontrado na região, garimpeiros vindos de diversas partes do país, principalmente de Minas Gerais, invadiram as imediações da cidade em busca das novas jazidas de pedras preciosas e trouxeram consigo a cultura caipira.

A formação dessa população é caracterizada pelos mamelucos ${ }^{6}$ paulistas, conhecidos historicamente como os bandeirantes que desbravaram as terras brasileiras em busca, inicialmente, de índios para serem escravizados. Sua economia era de subsistência e muito precária, e sua localização dispersa, quase nômade, variava de acordo com as possibilidades de melhora de vida

\footnotetext{
5 De acordo com Darcy Ribeiro (2006, p. 321), o cangaço "foi uma forma de banditismo típica do sertão pastoril, estruturando-se em bandos de jagunços vestidos como vaqueiros, bem armados, que percorreram as estradas do sertão em cavalgadas, como ondas de violência justiceira [...] todos fazendo do banditismo uma expressão de revolta sertaneja contra as injustiças do mundo.".

6 Mameluco é a expressão utilizada para se referir a uma pessoa nascida da miscigenação entre o branco e o índio.
} 
que surgiam.

Essa pobreza, que está na base tanto das motivações quanto dos hábitos do paulista antigo, é que fazia deles um bando de aventureiros sempre disponível para qualquer tarefa desesperada [...]. (RIBEIRO, 2006, p. 330).

A descoberta de ouro e pedras preciosas encheu essa população de esperança. No entanto, a dificuldade para a extração dos minérios e a necessidade de atravessadores para sua venda foram grandes empecilhos para a melhora de suas condições de vida. Durante a busca pelo ouro, a Coroa criou condições apenas para manter a riqueza de quem já era rico e garantir sua parcela da extração. Entretanto, o aglomerado de gente dos novos povoados que se formavam em torno das jazidas propiciou a continuidade do processo de miscigenação brasileira.

Nas zonas de mineração, a sociedade brasileira adquire feições peculiares como um desdobramento do tronco paulista, por influência dos brasileiros vindos de outras áreas e de novos contingentes europeus neles incorporados, e da presença de uma grande massa de escravos, tanto africanos quanto nativos, trazidos das antigas zonas açucareiras. (RIBEIRO, 2006, p. 339).

A grande contribuição estética dessa formação populacional foi a opulência dos estilos arquitetônicos do Barroco e do Rococó. Igrejas e casas magistrais, muitas preservadas até hoje, evidenciam a riqueza dos tempos áureos da mineração.

Tendo sofrido influência desses estilos, Lençóis teve o seu acervo arquitetônico colonial tombado pelo IPHAN, em 1973. Porém, ao contrário de cidades como Ouro Preto e Tiradentes, a arquitetura civil da cidade tem mais importância que a arquitetura religiosa. $O$ acervo é constituído por casas e sobrados da segunda metade do século XIX, que se destacam pelas cores vivas de sua alvenaria e esquadria. As portas e janelas têm formas predominantemente arqueadas e, nas edificações mais elaboradas, a fachada apresenta ornamentos, colunas e esculturas no estilo rococó.

\section{A tipografia e o vernacular}

A cultura popular é caracterizada pela espontaneidade e pela forma de expressão genuína de uma sociedade, tornando-se por isso, insumo para artistas e designers. Assim como o design vernacular impresso em placas, letreiros, cartazes e embalagens produzidos por artistas populares, que espalham na paisagem visual urbana a materialidade de nossa cultura.

Segundo a designer Fátima Finizola (2010, p. 14), "o rico universo popular brasileiro passa por um processo de deslocamento e tradução para os meios digitais, em que observamos uma tendência ao desenvolvimento de projetos tipográficos com inspiração na linguagem gráfica vernacular". Tal deslocamento é observado, por exemplo, nas fontes Brasilêro e Seu Juca, dos designers Crystian Cruz e Priscila Farias, respectivamente. Brasilêro é resultado de uma análise das formas particulares das letras encontradas em placas e muros das cidades brasileiras, enquanto Seu Juca é uma homenagem ao letrista popular pernambucano José Juvêncio Filho.

Iniciativas como essas corroboram o rico campo de possibilidades e experiências visuais que a linguagem gráfica popular oferece à prática do Design, se estabelecendo como importante veículo para a cultura e identidade de uma sociedade. Para além de decodificador desses signos e símbolos em produtos e mensagens, é papel social do designer valorizar e dar destaque a essas expressões e também, segundo Farias (2011), configurar identidades por meio delas. 
A criação tipográfica também carrega em si traços culturais e tecnológicos de seu contexto social. Dos primeiros tipos móveis ${ }^{7}$, que seguiam um estilo visual humanista em decorrência de seu vínculo inicial com a arte renascentista, às primeiras fontes digitais adaptadas à baixa resolução dos primeiros computadores e impressoras, vê-se um alinhamento do desenho tipográfico à intencionalidade ou necessidade de traduzir o seu contexto. O mesmo se observa nos desenhos de letras ou letterings ${ }^{8}$, produzidos pelos letristas populares. Sua criação empírica e informal reproduz as necessidades de seus clientes e os limites de sua técnica e suporte, mas também dá corpo à cultura visual na qual os artesãos estão inseridos.

\section{Análise dos letreiros comerciais de Lençóis}

A amostra registrada é de aproximadamente 60 letreiros, que, de início, foram classificados de acordo com sua técnica de confecção. Assim, foram identificadas quatro técnicas diferentes: a de produção manual, a de recorte de madeira a laser, a de recorte ou conformação do metal e a de impressão digital.

Figura 2 - Técnicas de confecção dos letreiros comerciais: da esquerda à direita, produção manual, recorte de madeira a laser, conformação do metal e impressão digital.
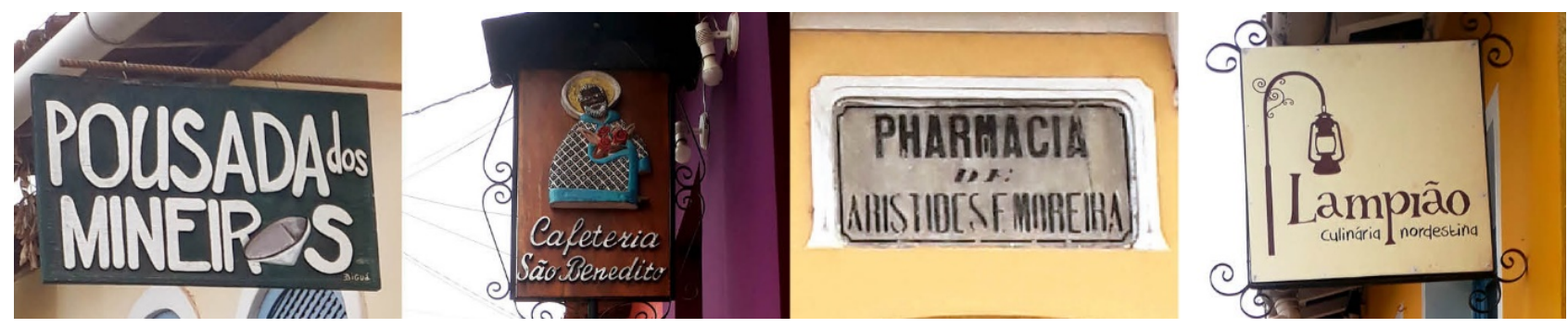

Fonte: a autora (2017).

Tal levantamento constatou que mais de $50 \%$ dos letreiros fotografados foram produzidos manualmente por letristas populares. Isso chama atenção, porque, ao contrário do que se observa em Lençóis, se nota nas grandes cidades, segundo Finizola (2010, p. 13), que "os letreiros populares pintados à mão disputam espaço com placas confeccionadas em vinil adesivo recortado ou impressões digitais", acarretando no desaparecimento gradual do ofício do letrista. Como o foco da análise desse estudo é justamente a produção manual, os letreiros das demais técnicas foram desconsiderados.

Em razão da necessidade de proteger a visibilidade dos casarios tombados, os letreiros comerciais da cidade devem seguir certos padrões determinados pelo IPHAN do estado baiano. As placas ou letreiros devem ter em média $50 \mathrm{~cm}$ de largura por $70 \mathrm{~cm}$ de altura e podem ser presos na parede por parafusos, ou pendurados na transversal do prédio por uma haste pequena, sendo esta última a opção mais utilizada. Não são permitidas pinturas de placas ou desenhos na própria fachada, assim como a colocação de faixas, cartazes, cavaletes ou banners

\footnotetext{
7 Tipos móveis é uma tecnologia de impressão inventada na China e aperfeiçoada pelo alemão Johannes Gutenberg, no início do século XV, que revolucionou a escrita ao possibilitar a produção em massa de livros.

8 Traduzido como letreiramento em português, o termo se refere, segundo Finizola (2010, p. 36), “à técnica de desenhar e construir conjuntos de letras por processo manual, mas que atualmente também pode ser desenvolvido por processos digitais".
} 
na frente das edificações tombadas. O estado de conservação dos letreiros também é fiscalizado. Foi possível verificar que todos os letreiros e casas observadas estavam de acordo com as determinações do IPHAN.

Durante a pesquisa, Gil das Pedras, letrista da cidade baiana, foi entrevistado ${ }^{9}$ com a finalidade de identificar a sua relação com a cidade e como esse vínculo impacta seu processo criativo. Gil nasceu no Rio de Janeiro, mas vive em Lençóis há mais de 30 anos. Segundo seu relato, ao chegar à cidade, conheceu o trabalho de alguns artesãos que utilizavam laje de argilito, uma formação rochosa particular da região, para a produção de letreiros e outros produtos. Sozinho, ele começou a experimentar o material e a aprender o ofício. Ele extrai a pedra a aproximadamente 30 $\mathrm{km}$ da cidade, para, em seguida, fazer seu polimento e corte com discos diamantados. A pedra pode ser pintada ou esculpida, mas o manuseio do argilito demanda certos cuidados, pois o seu pó é tóxico. Apesar de possuir catálogo de fontes para consulta, Gil afirma fazer adaptações e criações de letras em todos os trabalhos, inspiradas em temas relativos à cidade.

Ao todo foram analisados 17 letreiros, sendo seis deles reconhecidos como criações de Gil das Pedras. A autoria dos demais letreiros não foi identificada; dessa forma, o critério de escolha dos 11 letreiros restantes foi o nível de especialidade expressa na produção, já que muitos deles são produzidos por pessoas que não são letristas profissionais, como os próprios donos dos estabelecimentos. Apesar de haver certa irregularidade, inclusive nos letreiros produzidos por letristas especialistas, os produzidos por amadores apresentam ainda acabamentos mais grosseiros e desenhos de letras menos uniformes.

Figura 3 - À esquerda, letreiro desenvolvido por um letrista amador; à direita, um letreiro de Gil das Pedras.

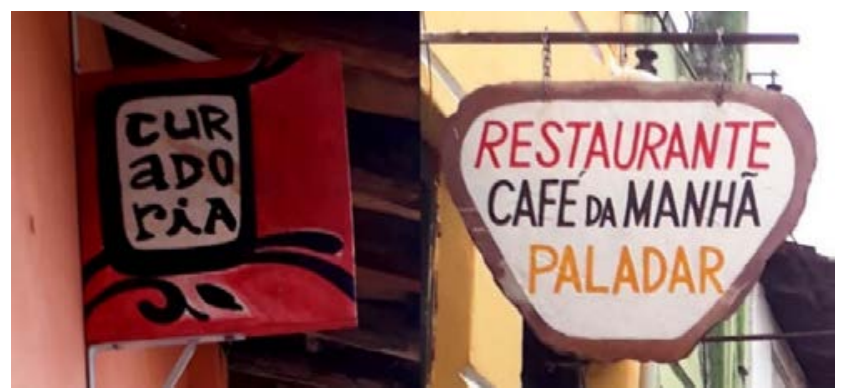

Fonte: a autora (2017)

No livro Tipografia vernacular urbana: uma análise dos letreiramentos populares (2010), a autora Fátima Finizola utilizou como método de análise de sua amostra uma associação dos conceitos dos escritores e designers Catherine Dixon e Michael Twyman. Para avaliação dos letreiros de Lençóis, considerou-se pertinente a utilização dos mesmos critérios, mas com ajustes necessários ao contexto deste trabalho.

Finizola inicia sua análise considerando os tipos de abordagem linguística e gráfica da linguagem, definidos por Twyman. Ele classifica a linguagem visual em dois canais diferentes, o gráfico e o não gráfico, e subdivide o gráfico em três modos de abordagem distintos, o verbal, o pictórico e o esquemático.

[...] a linguagem gráfica verbal compreende os caracteres ortográficos utilizados para a

9 Entrevista realizada por telefone no dia 15 de outubro de 2017. 
representação da escrita, enquanto a linguagem gráfica esquemática engloba aqueles artifícios gráficos utilizados para facilitar a organização visual do texto, como barras, fios, molduras etc. que geralmente não se enquadram na categoria pictórica. (FINIZOLA, 2010, p. 35).

Twyman também divide a linguagem gráfica verbal em dois aspectos: os intrínsecos e os extrínsecos. Os aspectos intrínsecos, segundo Finizola (2010, p. 49), "se referem aos elementos que definem a forma particular de cada letra", já os aspectos extrínsecos "se referem à relação entre os caracteres e a página impressa".

Para a observação dos aspectos intrínsecos dos artefatos de sua pesquisa, Finizola (2010) adotou oito atributos formais definidos pela designer Catherine Dixon: a construção, a forma, a proporção, a modulação, o peso, a serifa ${ }^{10}$ e os terminais ${ }^{11}$, os caracteres-chave e a decoração. Já o uso de cor, o alinhamento e a disposição das letras e o uso de elementos esquemáticos e pictóricos foram os aspectos extrínsecos considerados. Além dos itens escolhidos por Finizola, durante a pesquisa, foram observados também o uso de letras maiúsculas e minúsculas, o tipo de suporte (pedra, madeira, metal) e o formato do letreiro. Por fim, considerando a afirmação de Anastassakis $(2008$, p.7) de que os artefatos "objetificam processos culturais", foi avaliada a possível relação entre eles e a cultura local, através dos dados da análise dos atributos formais dos letreiros. A análise de cada um dos 17 letreiros foi feita como no exemplo abaixo.

Quadro 1 - Análise do letreiro de Fazendinha \& Tal.

Figura 3 - Letreiro de Fazendinha \& Tal.

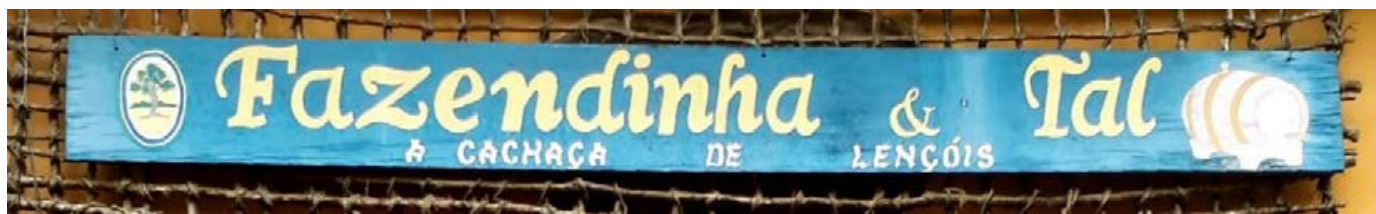

Fonte: a autora (2017).

Autoria Desconhecida.

Tipos de linguagem visual gráfica

Aspectos intrínsecos
Verbal e pictórica.

- Construção do conjunto de caracteres: contínua;

- Forma: curvas contínuas ovaladas com hastes paralelas. As hastes das letras do slogan são fraturadas;

- Proporção: a largura de algumas letras é levemente expandida. A altura-x é irregular;

- Modulação: há variação de contraste entre algumas hastes, mas principalmente nos terminais;

- Peso: bold e semibold;

- Serifas, terminais: com serifa, tipo Clarendon (primeira linha) e sem serifa (segunda linha). Os terminais variam entre retos e arredondados;

10 Serifa é o "traço ou barra que remata cada haste de uma letra". (MATSUSHITA, 2011, p. 129).

11 Terminais são "desenhos no final do braço, perna, ou bojo das letras". (MATSUSHITA, 2011, p. 129) 
- Decoração: as letras do texto da segunda linha são do tipo Fantasia;

- Caracteres-chave: as letras $f, t$ e $z$.

\section{Aspectos extrínsecos}

- Uso de cor: fundo azul, letras brancas e amarelas. A cor dos desenhos varia entre amarelo, marrom, verde, cinza e branco;

- Alinhamento e disposição das letras: centralizado, linear;

- Uso de maiúsculas e minúsculas: uso de letras maiúsculas e minúsculas;

- Material do suporte: madeira;

- Elementos esquemáticos e pictóricos: árvore e barril de bebida.
Relação entre o letreiro e a cultura local
O desenho da letra é irregular, apresentando correspondência com a caligrafia e o movimento da mão. A sinuosidade das serifas e alongamento dos terminais remetem a uma referência visual orgânica, que pode estar vinculada aos ornamentos rococós de algumas edificações da cidade.

Fonte: a autora (2017)

\subsection{Tipos de linguagem visual gráfica}

Cinco letreiros da amostra apresentaram apenas elementos da linguagem visual gráfica verbal. Onze apresentaram em sua composição elementos da linguagem visual gráfica verbal e pictórica e apenas um letreiro possuía, além destas duas linguagens, um elemento da linguagem visual gráfica esquemática.

Os elementos pictóricos escolhidos pelos letristas variaram entre desenhos representativos do tipo de comércio do estabelecimento, como frutas e cesta de pães, e desenhos simbólicos da cultura imagética da cidade, como arandelas coloniais e bateias para o garimpo.

\subsection{Aspectos intrínsecos}

O primeiro aspecto intrínseco analisado foi a construção. Quanto à construção, as letras podem ser consideradas contínuas, descontínuas, modulares, amorfas e com referência à ferramenta de trabalho. Onze letreiros apresentaram desenhos de letras de construção apenas contínua. Os demais variaram entre construções contínuas, amorfas e com referência a ferramenta de trabalho na mesma placa.

O segundo aspecto analisado foi a forma, que se refere aos componentes estruturais e ao tratamento dado às curvas e hastes da letra. Sete letreiros apresentaram construções geométricas de base retangular e sete construções curvilíneas de base ovalada. Observou-se duas ocorrências de letras com correspondência à caligrafia e ao movimento da mão. As hastes das letras eram predominantemente retas e, em apenas dois casos, levemente inclinadas.

O terceiro aspecto, a proporção, diz respeito a relação entre o tamanho das partes do desenho da letra (ascendente, descendente, altura- $\mathrm{x}^{12}$ etc.). Em cinco letreiros a proporção era

12 "Altura-x é a altura do corpo principal da letra minúscula (ou a altura de um x caixa-baixa), excluindo seus ascendentes e descendentes" (LUPTON, 2013, p. 33) 
normal em todas as letras. Nos demais, os letristas utilizaram como recurso condensar ou expandir as letras para encaixar a palavra no espaço da placa. Em decorrência disso, em mais de 50\% delas, as letras tinham altura-x irregular.

O quarto aspecto é a modulação, que segundo Finizola (2010, p. 51), "se caracteriza pela presença, ou não, de contraste de forma, ou seja, a diferença de espessura entre as hastes de uma letra". Mais de $50 \%$ das letras analisadas não apresentaram variação de espessura no desenho da haste. Em três casos, observou-se uma leve variação não intencional, principalmente nos terminais, decorrente de algum deslize durante a passagem do pincel.

O aspecto intrínseco seguinte, o peso, se refere a variação de espessura das letras de uma família tipográfica. Ele pode variar entre light, regular, bold, semibold e extrabold. Como a principal característica dos letreiros comerciais é se destacar no espaço urbano, constatou-se uma preferência dos letristas pelo uso do peso bold e semibold. Apenas dois letreiros apresentaram uso exclusivo do peso regular.

Quanto às serifas, a amostra apresentou apenas 5 letterings com serifas, que variavam entre os tipos Claredon, Latina e Antiga. 50\% dos letreiros possuíam terminais irregulares, ou seja, retos e arredondados em uma mesma palavra. Em seis letreiros os terminais se prolongavam leve ou acentuadamente, a ponto de formar uma seta, por exemplo.

Mais de $50 \%$ dos letreiros não possuem decoração nas letras. No entanto, observou-se algumas ocorrências de contorno de letras, prolongamento de terminais ou utilização de arabescos na lateral das hastes.

O último aspecto intrínseco é a definição de caracteres-chave. No entanto, o processo manual e espontâneo dos letristas imprimiu características peculiares em praticamente todas as letras, impossibilitando sua definição.

\subsection{Aspectos extrínsecos}

O primeiro aspecto extrínseco analisado foi a cor. Os artesãos utilizaram uma paleta de cores básicas, como preto, branco, vermelho, amarelo, azul e verde, com variação tonal limitada. Apenas três letristas utilizaram mais de três cores em um mesmo letreiro. Além disso, observou-se em todos os letreiros muita acuidade com o contraste e a legibilidade da informação.

Quanto ao aspecto alinhamento, constatou-se uma preferência exclusiva pelo uso do texto centralizado. Assim como, uma preferência pela disposição reta das letras. Em apenas dois casos a disposição era curvilínea e em um, inclinada.

Em relação ao tipo de caixa, a maioria dos artesãos optou por letras maiúsculas, com apenas cinco ocorrências de uso de letras minúsculas. No entanto, observou-se em um letreiro o uso de um desenho de letra comumente reconhecido como letra minúscula, aplicado como letra maiúscula.

O último aspecto intrínseco analisado é o tipo de suporte. Os letristas utilizaram madeira ou pedra de argilito como suporte para as placas, mas notou-se uma preferência pelo uso da pedra.

\subsection{Relação entre o letreiro e a cultura local}

O uso de uma pedra local como suporte da maioria das placas, escolhida inclusive pelo letrista entrevistado, foi identificado como uma característica expressiva nos letreiros, visto que a importância da extração de minérios na história de Lençóis é muito significativa. Da mesma maneira, 
em um dos letreiros, o artesão explorou sutilmente essa relação histórica, fazendo o contorno de um desenho a partir do contraste entre a pedra bruta e a pedra polida. Outra forte correspondência com o universo da mineração foi um letreiro com o formato de um diamante lapidado.

Em geral, a forma dos letreiros seguiu uma tendência de construção orgânica, com curvas sinuosas ao redor das placas, que lembram as linhas das figuras rococós das casas da cidade. Seguindo a referência desse estilo, algumas placas também possuem uma ornamentação curvilínea de metal disposta ao seu redor. Em outra produção, a pedra foi esculpida com uma textura de madeira, que deu ao letreiro um aspecto semelhante ao das matrizes de xilogravura.

Figura 4 - Letreiros com referências visuais da cultura local.
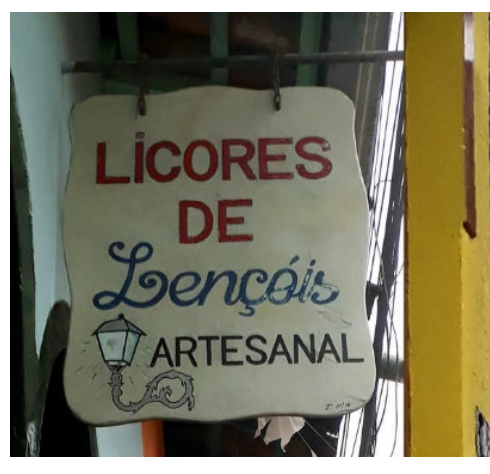
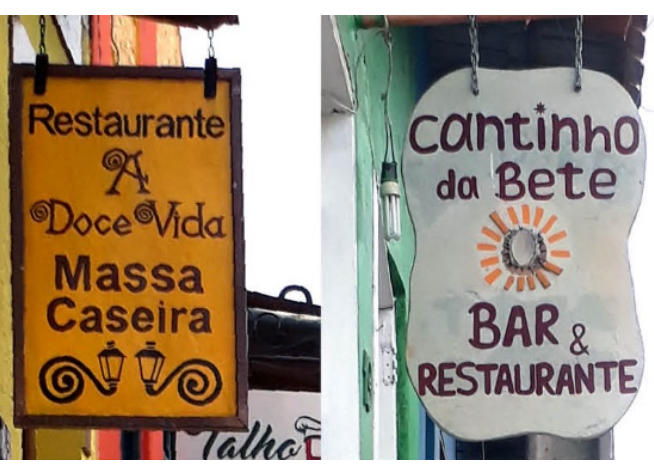

Fonte: a autora (2017).

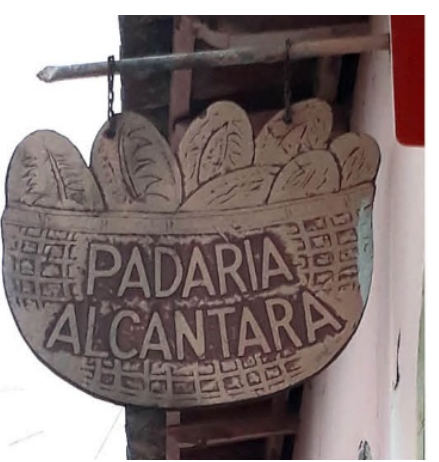

Boa parte dos letreiros que aplicaram ilustrações na composição utilizaram como tema a arquitetura local (arandela coloniais) e o garimpo (bateia). Os elementos esquemáticos também se resumem a curvas sinuosas.

Na tipografia, observou-se a utilização de dois recursos visuais que também fazem referência à arquitetura da cidade. O primeiro é o de prolongamento dos terminais das letras, criando, em alguns casos, uma ornamentação de estilo rococó. Além disso, muitas letras carregaram um aspecto caligráfico com formas sinuosas também ligado a esse estilo. O segundo é o de proporção do desenho das letras. Algumas possuem formas acentuadamente arredondadas, enquanto outras seguem um formato retangular que remete à proporção das portas e das esquadrias das casas coloniais.

Outra referência à xilogravura foi a substituição, em um dos letreiros, do ponto da letra $i$ pelo desenho de uma estrela irregular.

\section{Considerações finais}

"A arte está em todo o lugar da cidade. A arquitetura colonial e o próprio Parque, com sua beleza natural, inspiram". Com essa frase, Gil das Pedras confirma o que a análise dos letreiros apontou: a criação espontânea e autêntica somada à apurada percepção visual dos letristas populares imprimiu nos letreiros comerciais de Lençóis aspectos gráficos relativos à cultura local. $O$ inconsciente coletivo, sem dúvida, contribui para que artesãos de todo o mundo escolham artifícios visuais que traduzam, em seu trabalho, a cultura e a história de um lugar. No entanto, o que se observou na amostra analisada é que essas escolhas têm um caráter intencional, possivelmente devido à forte tradição oral dos habitantes da cidade, que são bastante familiarizados com a história local. 
A intensa influência gráfica da cultura caipira nos letreiros reflete a importância da mineração na formação da cidade. Nota-se que até hoje esse momento histórico faz parte da vida da população e seu período áureo está estampado na arquitetura da cidade. Entretanto, não se pode ignorar a relevância da cultura sertaneja, que também se transforma em recurso visual para os letristas.

Alguns fatores foram fundamentais para compreender com mais clareza a cultura e a produção gráfica vernacular de Lençóis. Um deles foi conhecer pessoalmente a cidade. Isso viabilizou um contato direto com os moradores e o local e possibilitou a identificação de certas nuances particulares da cultura da cidade. Outro fator crucial foi o tamanho do município e sua relação com a própria história. Lençóis é uma cidade pequena e tombada pelo patrimônio histórico, características que facilitaram a coleta da amostra e sobretudo o entendimento da formação da população e da cultura da região. Isso não quer dizer que esse tipo de estudo não possa ser realizado em uma cidade maior, no entanto, dividi-la em amostras menores durante a pesquisa trará um resultado mais representativo do todo. Também foi essencial associar o trabalho de Darcy Ribeiro à análise. A antropologia adicionou o fator humano à pesquisa e possibilitou identificar como os artifícios visuais e técnicos dos artesãos materializam a cultura e a população local nos letreiros.

Já é sabido que as escolhas gráficas de artesãos e designers são guiadas pela sua cultura e pela de seu público-alvo. Esta pesquisa constatou que, quando essa influência é assumida e aprofundada, os resultados estéticos podem ser mais amplos e satisfatórios. A associação da Antropologia e do Design gera um terreno rico e cheio de possibilidades para ambas as disciplinas. Mas, especificamente em relação ao Design, tal interdisciplinaridade somada à observação atenta à produção gráfica vernacular permite um entendimento mais profundo da pluralidade cultural brasileira e fortalece nossa identidade nacional, ao promover escolhas conscientes que representem o real valor de nossa cultura.

\section{Referências}

Anastassakis, Zoy. Apontamentos para uma antropologia do design. In: REUNIÃO BRASILEIRA DE ANTROPOLOGIA, 26., jun. 2008, Porto Seguro, 26. RBA. Porto Seguro: Centro de Convenções e CEFT, 2008.

BARBOSA, Andréa; CUNHA, Edgar Teodoro da. Antropologia e imagem. Rio de Janeiro: Jorge Zahar, 2006. (Passo-a-passo, 68).

BEZERRA, Almeida Amilcar. Movimento armorial x tropicalismo: dilemas brasileiros sobre a questão nacional na cultura contemporânea. In: ENCONTRO DE ESTUDOS MULTIDISCIPLINARES EM CULTURA (ENECULT), 5., maio 2009, V ENECULT. Salvador: Faculdade de Comunicação/UFBa, 2009.

BURY, John; OLIVEIRA, Myriam Andrade Ribeiro de. Arquitetura e arte no Brasil colonial. Brasília: IPHAN/Monumenta, 2006.

COSTELLA, Antonio F. Breve história ilustrada da xilogravura. Campos do Jordão: Mantiqueira/Museu Casa da Xilogravura, 2003.

FARIAS, Priscila Lena. Aprendendo com as ruas: a tipografia e o vernacular. In: BRAGA, Marcos da Costa. O papel social do design gráfico: história, conceitos e atuação profissional. São Paulo: Senac São Paulo, 2011. 
FINIZOLA, Fátima. Tipografia vernacular urbana: uma análise dos letreiramentos populares. São Paulo: Blucher, 2010.

FUNDAÇÃO DARCY RIBEIRO (FUNDAR). Biografia: Darcy Ribeiro. Disponível em: <http://www.fundar.org.br/fundacao/abre.php?abre=46>. Acesso em: 17 set. 2017.

INSTITUTO BRASILEIRO DE GEOGRAFIA E ESTATÍSTICA (IBGE). Lençóis. Disponível em: <https://cidades.ibge.gov.br/brasil/ba/lencois/panorama>. Acesso em: 16 jun. 2018.

INSTITUTO DO PATRIMÔNIO HISTÓRICO E ARTÍSTICO NACIONAL (IPHAN). Lençóis (BA). Disponível em: <http://portal.iphan.gov.br/pagina/detalhes/115>. Acesso em: 13 out. 2017.

Perguntas frequentes. Disponível em: <http://portal.iphan.gov.br/perguntasFrequentes? categoria=9>. Acesso em: 16 jun. 2018.

LUPTON, Ellen. Pensar com tipos: guia para designers, editores, escritores e estudantes. Traduzido por Cristina Fino. 2. ed. São Paulo: Cosac Naify, 2013.

MATSUSHITA, Raquel. Fundamentos gráficos para um design consciente. São Paulo: Musa, 2011.

O POVO brasileiro. Direção: Isa Grinspum Ferraz. Produção: Superfilmes. São Paulo: Paulus Vídeo, 2000. DVD (260 min.). colorido.

PORTAL DA PREFEITURA MUNICIPAL DE LENÇÓIS. História. Disponível em: <http://io.org.br/ba/lencois/historia>. Acesso em: 16 jun. 2018.

PREFEITURA DE MUCUGÊ. História de Mucugê. Disponível em: <http://www.mucuge.ba.gov.br/Home/f?idNoticia=0\&idForm=50>. Acesso em: 13 out. 2017.

RIBEIRO, Darcy. O povo brasileiro: a formação e o sentido do Brasil. São Paulo: Companhia das Letras, 2006.

RIBEIRO, José da Silva. Antropologia visual, práticas antigas e novas perspectivas de investigação. Revista de Antropologia, USP, São Paulo, v. 48, n. 2, 2005.

SUPERINTENDÊNCIA DO IPHAN NO ESTADO DA BAHIA. Nota técnica no 05/2013 - IPHAN/BA. Critérios para veiculação de publicidade para os centros históricos sob tutela do IPHAN/BA. 2013. 